\title{
Interaction Between Tomato spotted wilt virus N Protein Monomers Involves Nonelectrostatic Forces Governed by Multiple Distinct Regions in the Primary Structure
}

\author{
Mark Kainz, Pierre Hilson, Laura Sweeney, Erin DeRose, and Thomas L. German
}

First, third, and fourth authors: Department of Biology, Colgate University, 13 Oak Drive, Hamilton, NY 13346; second author: Functional Genomics Division, Department of Plant Systems Biology, Flanders Interuniversity Institute of Biotechnology (VIB), Ghent University, Technologie Park, 927, Ghent B-9052 Belgium; and fifth author: Department of Entomology, University of Wisconsin, 1630 Linden Drive, Madison 53706.

Accepted for publication 4 March 2004.

\begin{abstract}
Kainz, M., Hilson, P., Sweeney, L., DeRose, E., and German, T. L. 2004. Interaction between Tomato spotted wilt virus $\mathrm{N}$ protein monomers involves nonelectrostatic forces governed by multiple distinct regions in the primary structure. Phytopathology 94:759-765.

The ambisense RNA genome of Tomato spotted wilt virus (TSWV) is packaged by interaction with numerous copies of the virus encoded nucleocapsid $(\mathrm{N})$ protein to form a subvirion structure called a ribonucleoprotein (RNP). RNPs are central to the viral replication cycle because they, and not free viral RNA, serve as templates for viral gene expression and genome replication. $\mathrm{N}$ protein monomers bind to viral RNA molecules in a cooperative manner. We have examined regions of the $\mathrm{N}$ protein
\end{abstract}

ABSTRACT that are involved in the $\mathrm{N}-\mathrm{N}$ interactions that likely contribute to the cooperative binding of $\mathrm{N}$ to viral RNA. We created random and alanine scanning mutants of $\mathrm{N}$ and then screened the mutants for defects in $\mathrm{N}-\mathrm{N}$ interaction using reverse and forward yeast two-hybrid assays. Our experiments identified residues in three distinct regions of the primary structure of the protein, residues 42 to 56,132 to 152 , and in the Cterminal 26 amino acids, that contribute to $\mathrm{N}-\mathrm{N}$ dimerization or multimerization. The interactions between $\mathrm{N}$ monomers mediated by the residues we identified are of a nonelectrostatic nature.

Additional keyword: tospovirus.
Agricultural problems caused by weeds, insects, nematodes, fungi, and bacteria can be addressed by the application of specific chemical compounds that target points in the life cycle that are uniquely essential to the growth, maturation, reproduction, or dissemination of the offending agent. Designing such strategies to control diseases caused by viral pathogens presents a unique challenge. In contrast to organisms with a cellular organization, the association of viral pathogens with the host cell is of a qualitatively different and extremely intimate nature. Indeed, viral and host cell contents are not separated by membranes during replication of the viral genome, synthesis of viral structural components, or assembly of progeny virus particles. Viruses are obligately dependent on co-opting host cellular synthetic apparatii as well as metabolic pathways and energy generation systems for production of viral genetic material, protein components, and virus particle dissemination. Treatments that interfere with viral activities often have severe consequences to the normal functioning of the host. Thus, successful development of viral disease intervention strategies requires detailed understanding of the processes required for the viral replication cycle to identify specific ones that are unique to the pathogen and distinct from those required for normal functioning of the host cell. Tospoviruses are plant pathogens of major economic importance $(2,7)$ and the viral nucleocapsid $(\mathrm{N})$ protein contributes to the viral replication cycle in a structural and, perhaps, regulatory manner via its role in the formation of ribonucleoproteins (RNPs).

Corresponding author: T. L. German; E-mail address: TLG@entomology.wisc.edu

Publication no. P-2004-0428-01R

(c) 2004 The American Phytopathological Society
RNPs are structural features of Tomato spotted wilt virus (TSWV) virions as well as the virions of all members of the family Bunyaviridae $(6,8,21)$. The three viral genomic RNA molecules each are encapsidated by multiple copies of the virus encoded $\mathrm{N}$ protein to form RNPs $(6,8,21)$. In addition, a few copies of the viral L protein, a putative RNA-directed RNA polymerase, are associated with RNPs $(3,6,21,25)$. The RNPs are central to the infection cycle of TSWV and other bunyaviruses because they, and not naked viral genomic RNA, serve as templates for both viral gene transcription and genome replication $(6,21)$. An overview of current thinking regarding the processes of replication and expression of the ambisense TSWV genome is diagrammed in Figure 1 (for a review see reference 2). Virion RNA (vRNA) enters the cell in the form of an RNP encapsidated by $\mathrm{N}$ protein and serves as a template either for transcription of negative sense genes (e.g., L, GnGc, or N) or as a template for synthesis of viral complement RNA (vcRNA). In order for vcRNA to serve as template for synthesis of progeny vRNA molecules or as template for transcription of positive sense gene (e.g., NSm or NSs), it must first be encapsidated by $\mathrm{N}$ protein. The requirement for template RNPs (in both $\mathrm{v}$ and $\mathrm{vc}$ polarity) suggests a central role for $\mathrm{N}$ protein in the TSWV infection cycle that ultimately is responsible for pathogenesis and plant disease. The molecular determinants that govern assembly of TSWV and other bunyavirus RNPs reside in both the viral $\mathrm{N}$ protein and the viral genomic RNA molecules $(10,16,18,22,28)$.

One feature of the N protein-viral RNA interaction is the cooperative manner in which $\mathrm{N}$ binds RNA. The binding of various $\mathrm{N}$ protein preparations to their cognate RNA molecules has been reported as either weakly or highly cooperative $(10,16,18)$. This property of RNP formation suggests a model in which neighboring $\mathrm{N}$ proteins in an RNP interact with one another. A requirement 
of such a model is that $\mathrm{N}$ protein molecules have surfaces that interact with other $\mathrm{N}$ proteins.

$\mathrm{N}$ protein interactions have been studied in TSWV. Uhrig et al. (23) used yeast two-hybrid and solution interaction assays to study the interaction of full-length, $\mathrm{N}$ - and $\mathrm{C}$-terminal deletions, and a mutant $\mathrm{N}$ protein that contained two single amino acid substitutions. They suggested that monomers of TSWV N interact (in the absence of TSWV RNA) via hydrophobic forces in a socalled "head-to-tail" fashion. The head-to-tail model suggests that that residues in the $\mathrm{N}$-terminal portion of one monomer interact with residues in the $\mathrm{C}$-terminal portion of another $\mathrm{N}$ monomer to form dimers and ultimately multimers. The report that peptides corresponding to C-terminal sequences of TSWV N protein interact with $\mathrm{N}$ proteins from several tospoviruses in yeast two-hybrid assays is consistent with the head-to-tail model (19).

The head-to-tail model appears to be not universally valid for describing interaction between $\mathrm{N}$ proteins of different bunyaviruses. Data from a number of in vitro, yeast and mammalian two-hybrid and computer analysis studies of $\mathrm{N}$ proteins from animal-infecting bunyaviruses are consistent with a "head-to-head" model in which two or more $\mathrm{N}$ monomers interact via residues in the $\mathrm{N}$-terminal portion of the protein $(4,12,13)$. In addition, interactions involving residues located in regions of the protein other than the $\mathrm{N}$ - and $\mathrm{C}$ termini have been demonstrated to contribute to the formation or stability of hantavirus $\mathrm{N}$ protein dimers and multimers $(4,13,29)$. It remains to be determined whether RNPs of different bunyaviruses assemble by common or different mechanisms. It may be that models describing interactions governing RNP formation in animal-infecting bunyaviruses are of limited usefulness for understanding RNP structure in plant-infecting tospoviruses. Alternatively, it may be that RNP formation is a fundamentally conserved process for all members of the family Bunyaviridae. Thus, a complete understanding of RNP formation in tospoviruses requires further examination of the determinants of $\mathrm{N}-\mathrm{N}$ interaction.

We have examined and refined a model for interactions between TSWV N protein molecules. Using alanine (ala) scanning
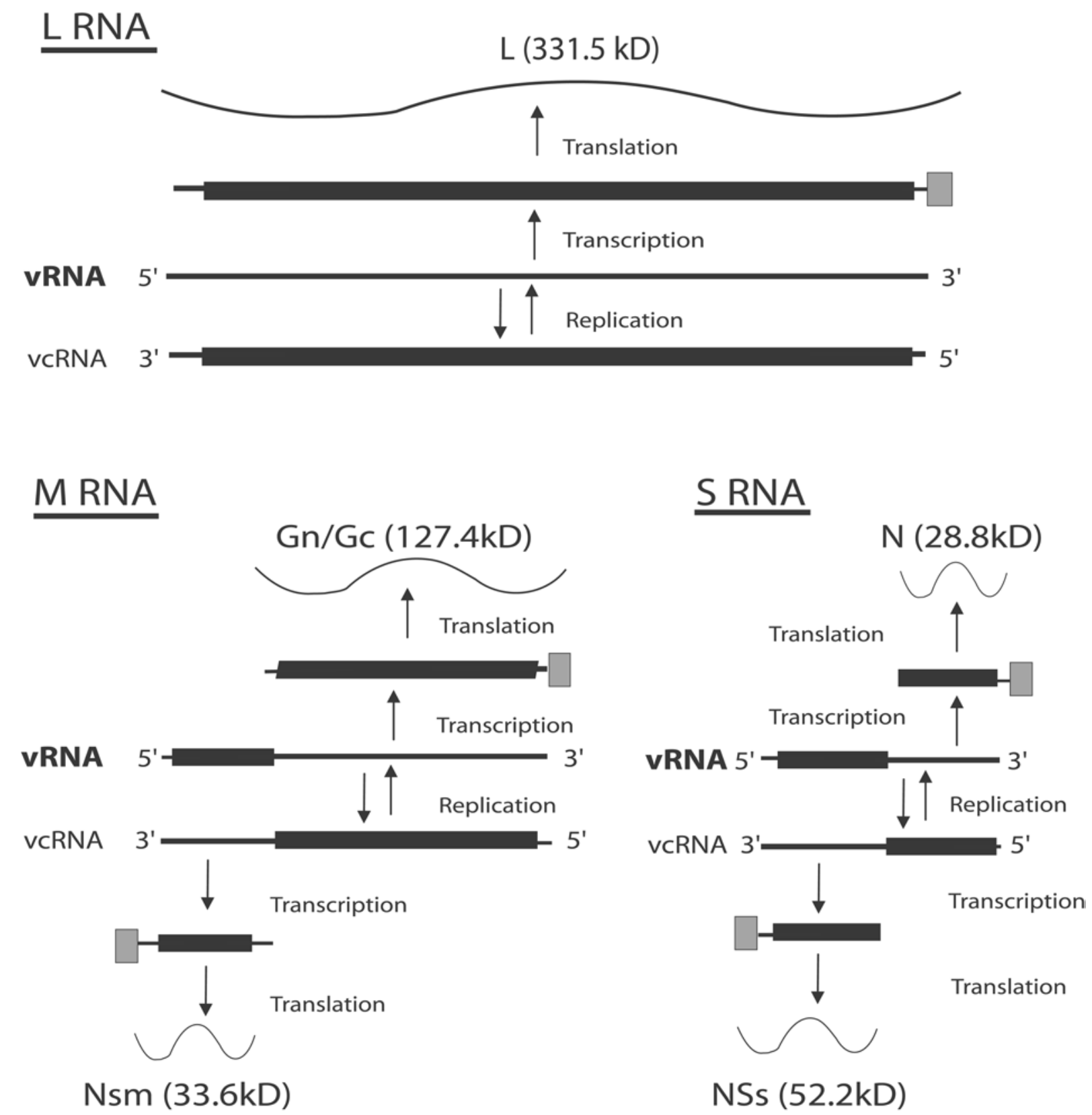

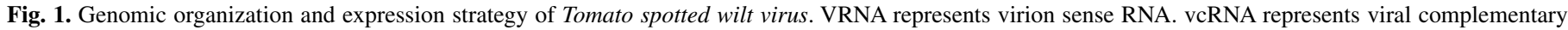

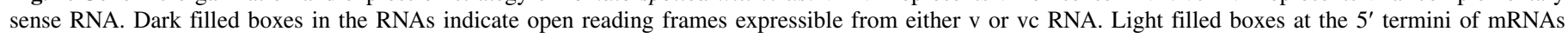
represent nontemplated cap structures. Thin flexuous lines represent virus encoded proteins. 
mutagenesis and yeast two-hybrid assays, we have identified positions in the $\mathrm{N}$ protein in addition to those reported by Uhrig et al. (23) that contribute to $\mathrm{N}$ protein dimerization and multimerization.

\section{MATERIALS AND METHODS}

Yeast two-hybrid system. Our yeast two-hybrid analysis system was derived from one developed by Vidal and colleagues (26) and from the Matchmaker system marketed by Clontech (Palo Alto, CA). All yeast cell experiments were performed in Saccharomyces cerevisae strain MaV203 (MATa, leu2-3,112, trp1-

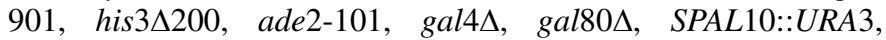
GAL1::lacZ, HIS3 $3_{\mathrm{UAS} G A L 1}:: H I S 3 @ L Y S 2, c a n 1^{\mathrm{R}}$, cyh $2^{\mathrm{R}}$ ) (26). Protein fusions of TSWV $\mathrm{N}$ and the Gal4 DNA binding domain (N-DB) were expressed from pGBT9 (Clontech). This yeast-Escherichia coli shuttle vector allows for fusion proteins to be expressed under control of the yeast ADH promoter and contains the $2 \mu$ yeast origin of replication and the TRP1 nutritional marker. Protein fusions of TSWV N and the Gal4 transcription activation domain (N-AD) were expressed from pACT2 (Clontech). This yeast $-E$. coli shuttle vector is similar to pGBT9 except that it contains the $L E U 2$ nutritional marker. In our system, interaction between the $\mathrm{N}$ protein moieties in the N-DB and N-AD fusions reconstitutes Gal4 transcription activator activity and enables expression of chromosomal HIS3, URA3, and lacZ reporter genes. We used five yeast strains (the generous gift of $\mathrm{M}$. Vidal and colleagues, Dana Farber Cancer Institute, Boston) that contained plasmids expressing $\mathrm{AD}$ and $\mathrm{DB}$ fusions that interacted with strengths that varied from no interaction to strong interaction (26) as controls in our yeast two-hybrid plate assays. Yeast culture media was as described by Adams et al. (1). Yeast transformations were by the LiOAc/ssDNA/PEG method (9).

Construction of TSWV $\mathbf{N}$ yeast two-hybrid plasmids. The TSWV N open reading frame (ORF) was amplified from extracts of Datura stramonium leaves infected with the TSWV Hawaiian isolate (24) by reverse-transcription polymerase chain reaction (RT-PCR). The reaction was primed with oligonucleotides that annealed to the $5^{\prime}$ and $3^{\prime}$ ends of the N ORF (oligonucleotide sequences: 5'-TCATCATGTCTAAGGTTAAGCTCA-3' and 5'-TTTAAGCAAGTTCTGTGAGTTTTG-3'). The RT-PCR yielded the expected size fragment (approximately $775 \mathrm{bp}$ ). This fragment was next amplified by PCR for cloning into either the AD or the $\mathrm{DB}$ vectors using primer sets that (i) contained Gal4 $\mathrm{AD}$ sequences and 5' N ORF sequences (5'-GATGATGAAGATACCCCACCAAACCCAAAAAAAGAGGGTGGGTCGACCCCGGGAATTCA$\left.3^{\prime}\right)$ and contained $\mathrm{ADH}$ terminator sequences and $3^{\prime} \mathrm{N}$ ORF sequences (5'-CCACCGCGGTGGCGGCCGTTACTTACTTAGAGCTCGACGTCTTACTTACTTAGCGGCCG-3') or (ii) contained Gal4 DB sequences and 5' N ORF sequences (5'-AGTAGTAACAAAGGTCAAAGACAGTTGACTGTATCGTCGAGGTCGACCCCGGGAATTCA-3') and contained ADH terminator sequences and $3^{\prime} \mathrm{N}$ ORF sequences (5'-CCACCGCGGTGGCGGCCGTTACTTACTTAGAGCTCGACGTCTTACTTACTTAGCGGCCG-3'). The resulting PCR products were recombined into SpeI linearized pPC86 (7), an intermediate N-AD vector, or into SpeI linearized pPC97 (7), an intermediate N-DB vector using the gap-repair technique (14). The intermediate vectors shared sequences with either Gal4 AD and the ADH terminator or Gal4 DB and the $\mathrm{ADH}$ terminator which allowed gap repair mediated construction of pACT2- $\mathrm{N}_{(\mathrm{wt})}$ (the N-AD plasmid) or pGBT9- $\mathrm{N}_{(\mathrm{wt})}$ (the N-DB plasmid) using standard techniques (14). The integrity of the constructs was confirmed by DNA sequencing.

Random mutagenesis and selection of interaction-defective $\mathbf{N}$ alleles by reverse two-hybrid assay. We exploited the high error rate of Taq DNA polymerase (30) to generate mutations in the $\mathrm{N}$ domain of the $\mathrm{N}-\mathrm{AD}$ fusion protein and then used a reverse two-hybrid assay $(26,27)$ to identify mutants defective in $\mathrm{N}-\mathrm{N}$ interaction. We amplified the N ORF plus approximately $125 \mathrm{bp}$ of sequence on both the $5^{\prime}$ and the $3^{\prime}$ end of the ORF from pPC86-N using AD-seq (5'-CGCGTTTGGAATCACTACAGGG$\left.3^{\prime}\right)$ and TERM-seq (5'-GGAGACTTGACCAAACCTCTGGCG$3^{\prime}$ ) oligonucleotides (which anneal to sequences that flank the $\mathrm{N}$ gene in both AD fusion plasmids, pPC86 and pACT2) in four independent PCRs. The amplified fragments (containing libraries of potential mutants which we denote as $\mathrm{N}^{*}$ ) were cloned into Bam HI linearized pACT2 using the gap-repair method (14) by transforming yeast strain MaV203 containing pGBT9- $\mathrm{N}_{(\mathrm{wt})}$ with the linearized plasmid and the PCR products. Each of the PCRs was gap-repair cloned independently and subsequent transformants were maintained as independent populations. Transformants containing both pGBT9-N $\mathrm{N}_{(\mathrm{wt})}$ (N-DB plasmid) and pACT2-N* were selected by plating cells on media lacking leucine (leu) and tryptophan (trp) (SC-L-T). We then used a reverse two-hybrid assay to identify transformants bearing mutant pACT2-N* plasmids that abrogated $\mathrm{N}-\mathrm{N}$ interaction. Transformants were replica plated on media amended with $0.15 \%$ 5-fluroorotic acid (5-FOA) (Toronto Research Chemicals) (SC-L-T+FOA). Cells that expressed URA3 (by virtue of $\mathrm{N}-\mathrm{N}$ interaction-mediated Gal4 transcription activation activity) were able to metabolize 5-FOA and did not grow. However, cells that did not express URA3 (because abrogated $\mathrm{N}-\mathrm{N}$ interactions prevented reconstitution of Gal4 transcription activation activity) were unable to metabolize 5-FOA and grew. Transformants growing more vigorously than cells transformed with pGBT9- $\mathrm{N}_{(\mathrm{wt})}$ and $\mathrm{pACT} 2-\mathrm{N}_{(\mathrm{wt})}$ were selected for further analysis.

The presence and correct size of the $\mathrm{N}$ gene insert in pACT2$\mathrm{N}^{*}$ clones extracted from cells growing on SC-L-T+FOA was determined by PCR amplification using AD-SEQ and TERM-SEQ oligonucleotides. Cells with pACT2-N* plasmids bearing an $\mathrm{N}$ gene size insert ( 1,025 versus 480 bp for empty vectors) were reassayed to confirm abrogation of $\mathrm{N}-\mathrm{N}$ interaction by virtue of low to no expression of the URA 3 and HIS3 reporters. Cells were patched on SC-L-T+FOA (URA3 assay) and on media lacking leu, trp, and histidine (his) and amended with $50 \mathrm{mM} 3$-aminotriazole (SC-L-T-H+3AT) (HIS3 assay). Each test plate also was patched with cells bearing the five control yeast two-hybrid calibration plasmid pairs $(26,27)$. Cells that exhibited moderate to robust growth on SC-L-T+FOA and weak to no growth on SC-L$\mathrm{T}-\mathrm{H}+3 \mathrm{AT}$ relative to the control strains were analyzed further.

Plasmids were isolated from yeast cells using the EZ Yeast plasmid prep kit (Genotech) and used to transform competent E. coli strain DH5 $\alpha$. E. coli transformants bearing only pACT2$\mathrm{N}_{(\mathrm{wt})}$ derivatives and not pGBT9- $\mathrm{N}_{(\mathrm{wt})}$ were identified by colony hybridization (20) using probes for the LEU2 marker (pACT2$\mathrm{N}_{(\mathrm{wt})}$ ) and the TRP1 marker (pGBT9- $\mathrm{N}_{(\mathrm{wt})}$ ). Plasmids were prepared from bacterial cultures identified in the hybridization as containing the leu marker (pACT2) and lacking the trp marker (pGBT9). The location and nature of mutations in the pACT2-N* plasmids were determined by DNA sequencing of the entire $\mathrm{N}$ ORF and flanking sequence.

Construction and analysis of ala mutants. We replaced individual native amino acid residues in the $\mathrm{N}$-AD fusion protein with ala at positions identified in the initial screen using oligonucleotide-directed mutagenesis. Mutants were obtained by amplifying the TSWV N gene and flanking plasmid sequences from pACT2$\mathrm{N}_{(\mathrm{wt})}$ using a three oligonucleotide method $(11,15)$. In brief, a region of pACT2- $\mathrm{N}_{(\mathrm{wt})}$ that contained the TSWV N gene as well as sequences from the Gal 4 activation domain and from the $\mathrm{ADH}$ terminator was amplified using Vent DNA polymerase (New England Biolabs) in the presence of Taq DNA ligase (New England Biolabs) in a reaction that contained AD-seq and TERM-seq oligonucleotides along with a specific mutagenic oligonucleotide (Integrated DNA Technologies) that contained an ala codon in place of the native codon (oligonucleotide sequences available upon request). The amplified fragment was digested with SmaI 
and $S a c I$ and used to replace the analogous segment in pACT2$\mathrm{N}_{(\mathrm{wt})}$. The presence of the ala substitution and the absence of other mutations was verified by sequencing the entire region of pACT2-N replaced by the amplified fragment for each mutant construction.

Yeast strain MaV203 containing pGBT9- $\mathrm{N}_{(\mathrm{wt})}$ was transformed with pACT2-N plasmids (wt or ala mutant). Transformants were selected by plating on SC-L-T. Interaction between $\mathrm{N}$ proteins was assessed by measuring expression of the chromosomal lac $\mathrm{Z}$ reporter using a quantitative solution $\beta$-galactosidase assay (onitrophenyl-galactose [ONPG] hydrolysis) of permeabilized cells (1). Transformants were cultured in SC-L-T broth prior to assay. $\beta$-Galactosidase was measured in duplicate from eight independent transformants for each ala substitution mutant (a total of 16 assays for each ala substitution mutant). Each mutant was assayed in parallel with wt N-AD-expressing cells and with green fluorescent protein-AD (GFP-AD)-expressing cells as positive and negative controls. Expression of lac Z in cells bearing ala mutants was normalized to that of cells bearing pACT2- $\mathrm{N}_{(\mathrm{wt})}$. The $\mathrm{N}-\mathrm{N}$ interaction phenotype of the ala mutants also was confirmed by culturing transformants on SC-L-T-H+3AT.

We determined the size, stability, and relative abundance of the $\mathrm{N}-\mathrm{AD}$ fusion proteins in yeast cells by Western blot analysis. Yeast strain MaV203 cells containing pACT- $\mathrm{N}_{(\mathrm{wt})}$, one of the various pACT2- $\mathrm{N}_{(\mathrm{wt})}$, or pACT2-GFP (a negative control) were grown overnight in SC-L broth, diluted into nonselective yeast peptone dextrose broth, and grown to early log phase (absorbance at $600 \mathrm{~nm}\left[A_{600}\right]=0.5$ to 0.7$)$. Protein was extracted from cells using the sodium dodecyl sulfate (SDS)/urea method (17). Protein yields were measured using a bicinchoninic acid protein assay kit (Pierce, Rockford, IL). Equal amounts of protein were resolved by SDS-polyacrylamide gel electrophoresis and transferred to nitrocellulose membranes. N-AD fusion proteins were probed using a rabbit polyclonal antiserum raised against purified TSWV $\mathrm{N}$ protein (provided by J. Sherwood, University of Georgia) and antigen or antibody complexes were detected using an ECL-Plus kit (Amersham, Piscataway, NJ). Duplicates of each sample were run on parallel gels, transferred to nitrocellulose, and probed with a rabbit polyclonal antiserum raised against yeast transcription factor TFIIB (provided by B. Hoopes, Colgate University).

\section{RESULTS}

We used a yeast two-hybrid system to investigate interactions between $\mathrm{N}$ protein monomers. Our system has three reporters, $H I S 3, U R A 3$, and lacZ (26). When TSWV N gene sequences were cloned in pACT2 and pGBT9 to yield Gal4 transcription activation domain-N fusions and Gal4 DNA binding domain-N fusions and these plasmids were present in MaV203, all three reporters

TABLE 1. Summary of substitution mutants in Tomato spotted wilt virus $\mathrm{N}$ obtained by random polymerase chain reaction mutagenesis defective in $\mathrm{N}-\mathrm{N}$ interaction as measured by yeast forward and reverse two-hybrid assays

\begin{tabular}{ll}
\hline Mutant allele designation & Changes (wt-residue-mutant) \\
\hline 30 & I144T \\
180 & S155P \\
191 & L152P \\
71 & S119P \\
167 & M145V \\
158 & L42P \\
250 & F56S \\
25 & S123P, S222G \\
68 & L114P, F159S \\
262 & C53Y, G131R \\
271 & V196L, N205S \\
301 & A143V, K175E \\
133 & L132S, E206G, S229G \\
244 & M91T, V209G, K250N \\
259 & E106G, A167T, F246L \\
\hline
\end{tabular}

were expressed. MaV203 cells transformed with both pACT2$\mathrm{N}_{(\mathrm{wt})}$ and pGBT9- $\mathrm{N}_{(\mathrm{wt})}$ were able to (i) grow on media lacking histidine but amended with $50 \mathrm{mM}$ 3-aminotriazole (SC-L-T$\mathrm{H}+3 \mathrm{AT}$ ), (ii) grow on media lacking uracil (SC-L-T-U), and (iii) express $\beta$-galactosidase as determined using a filter-based $\mathrm{X}$-gal assay (data not shown). This result was expected and confirms the data published by Uhrig and colleagues (23). We found no evidence of self activation of reporter expression in cells transformed singly with either pACT2- $\mathrm{N}_{(\mathrm{wt})}$ or pGBT9- $\mathrm{N}_{(\mathrm{wt})}$ or in cells doubly transformed with pACT2-GFP (which encodes a GFP-AD fusion)

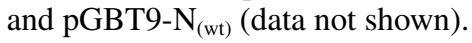

Random mutants in the TSWV $\mathbf{N}$ gene. We exploited the natural error rate of Taq DNA polymerase to generate a library of mutants in pACT2-N. Yeast strain MaV203 containing pGBT9$\mathrm{N}_{(\mathrm{wt})}$ was transformed with the pACT2-N* $\mathrm{N}^{*}$, doubly transformed cells were selected by plating on SC-L-T, and these then were screened for interaction-defective alleles of $\mathrm{N}$ by replica plating on media amended with 5-FOA (SC-L-T+FOA) in a reverse twohybrid selection. Of 1,298 transformants tested, we identified 38 candidate mutants based on the presence of an $\mathrm{N}$ gene-sized fragment in pACT2 and on the moderate to robust growth of the cells on SC-L-T+FOA. Plasmids were isolated from these yeast cells and position and nature of the mutations were determined by DNA sequencing. From the 38 candidates, we identified 23 nonsense and frameshift mutants (data not shown) as well as $15 \mathrm{~N}$ alleles that contained one, two, or three amino acid changes but otherwise encoded a full-length $\mathrm{N}$ protein (Table 1). Yeast cells (strain MaV203) containing pGBT9- $\mathrm{N}_{(\mathrm{wt})}$ that were retransformed with pACT2 bearing the mutant $\mathrm{N}$ alleles grew on media amended with $0.15 \%$ 5-FOA and did not grow on media lacking histidine and amended with $50 \mathrm{mM} 3 \mathrm{AT}$, thereby confirming the $\mathrm{N}-\mathrm{N}$ interaction-defective phenotype.

A number of the random mutants isolated suffered radical changes in amino acid side chains at particular residues. For example, in mutant 250 , the native phenylalanine at residue 56 was changed to serine and in mutant 71 the native serine at position 119 was changed to proline (Table 1). Although the interaction-

TABLE 2. Summary of normalized $l a c \mathrm{Z}$ reporter gene expression measured in yeast two-hybrid assays in cells transformed with alanine substitution mutants in pACT2-N

\begin{tabular}{lcc}
\hline Residue $^{\mathrm{a}}$ & Amino acid change & $\beta$-Galactosidase activity \\
\hline 42 & L to A & 39 \\
53 & C to A & 31 \\
56 & F to A & 6 \\
91 & M to A & 100 \\
106 & E to A & 97 \\
114 & L to A & 95 \\
119 & S to A & 105 \\
123 & S to A & 88 \\
131 & G to A & 92 \\
132 & L to A & 59 \\
144 & I to A & 3 \\
145 & M to A & 42 \\
152 & L to A & 51 \\
155 & S to A & 102 \\
159 & F to A & 99 \\
175 & K to A & 148 \\
196 & V to A & 94 \\
205 & N to A & 93 \\
206 & E to A & 100 \\
209 & V to A & 109 \\
222 & S to A & 100 \\
229 & S to A & 96 \\
246 & F to A & 653 \\
250 & K to A & 104 \\
\hline & &
\end{tabular}

a Location in Tomato spotted wilt virus $\mathrm{N}$ primary structure.

${ }^{\mathrm{b}}$ Activity relative to wild type, measured by o-nitrophenyl-galactose hydrolysis. Expression in cells bearing $\mathrm{pACT} 2-\mathrm{N}_{(\mathrm{wt})}$ is set at 100 , values are the mean of 16 assays. 
defective phenotype of such mutants was reproducible, interpretation of the cause of the phenotype was not straightforward. A particular substitution may have altered a specific surface for $\mathrm{N}-$ $\mathrm{N}$ interaction or the phenotype may have been the result of a misfolded protein. Therefore, we did not further analyze the random mutants but, instead, constructed ala substitution mutants at the residues identified in the initial screen. Ala substitutions have been demonstrated to not significantly affect the overall structure or folding of a protein (5).

Site-directed ala mutants in the TSWV N gene. We used sitedirected mutagenesis to change individual codons in $\mathrm{pACT} 2-\mathrm{N}_{(\mathrm{wt})}$ from the native sequence to an ala codon in order to express AD$\mathrm{N}$ fusions that contained single ala substitutions at residues identified in the screen described above. We then determined the ability of the ala substitution mutant $\mathrm{N}$ proteins to interact with wildtype $\mathrm{N}$ by transforming MaV203 bearing pGBT9- $\mathrm{N}_{(\mathrm{wt})}$ with $\mathrm{pACT} 2-\mathrm{N}_{(\mathrm{ala})}$ or $\mathrm{pACT} 2-\mathrm{N}_{(\mathrm{wt})}$ and measuring lac $\mathrm{Z}$ reporter gene expression. Our assay is a quantitative solution assay (1) that measures the hydrolysis of ONPG, an artificial $\beta$-galactosidase substrate. Thus, we can estimate the relative severity of the defect, if any, in interaction between the ala mutant and wild-type N. All $\mathrm{AD}-\mathrm{N}_{(\mathrm{ala})}$ fusions were assayed in parallel with $\mathrm{AD}-\mathrm{N}_{(\mathrm{wt})}$ (a positive control) and AD-GFP (a negative control). For comparison, expression of lac $\mathrm{Z}$ in cells bearing the various pACT2-N $\mathrm{N}_{(\text {ala) }}$ plasmids was normalized to that measured in cells bearing pACT2$\mathrm{N}_{(\mathrm{wt})}$, which was set at $100 \%$. In one typical experiment, activity in MaV203 transformed (i) with both pACT2-N $(w t)$ and pGBT9$\mathrm{N}_{(\mathrm{wt})}$ was $17( \pm 2.3)$ units, (ii) with pACT2-GFP and pGBT9- $\mathrm{N}_{(\mathrm{wt})}$ was $0.5( \pm 0.1)$ units, (iii) with either pACT2- $\mathrm{N}_{(\mathrm{wt})}$ or $\mathrm{pGBT} 9-\mathrm{N}_{(\mathrm{wt})}$ alone was $0.4( \pm 0.1)$ units, (iv) with pACT2-N $\mathrm{N}_{(42 \mathrm{~A})}$ and pGBT9$\mathrm{N}_{(\mathrm{wt})}$ was $6.6( \pm 1.1)$ units, (v) with pACT2- $\mathrm{N}_{(144 \mathrm{~A})}$ and pGBT9$\mathrm{N}_{(\mathrm{wt})}$ was $0.6( \pm 0.1)$ units, and (vi) with pACT2- $\mathrm{N}_{(246 \mathrm{~A})}$ and pGBT9- $\mathrm{N}_{(\mathrm{wt})}$ was $110.5( \pm 5.2)$ units. Reporter gene activity of yeast expressing $\mathrm{AD}-\mathrm{N}_{(\mathrm{ala})}$ normalized to that measured in cells expressing $\mathrm{AD}-\mathrm{N}_{(\mathrm{wt})}$ is presented in Table 2 and Figure 2. Ala substitution at most of the residues in the $\mathrm{N}$ protein tested did not appreciably affect lacZ expression (Table 2; Fig. 2). However, replacement of native residues with ala in two regions (positions 42,53 , and 56 and positions 132, 144, 145, and 152) resulted in reduced expression of the reporter (6 to $39 \%$ and 3 to $59 \%$ of levels measured with the wild type) (Table 2; Fig. 2). Ala substitutions at two residues, 175 and 246, resulted in increased reporter expression (Table 2; Fig. 2).

The interaction phenotypes of the ala mutants observed using the $\beta$-galactosidase assay were confirmed by culturing cells on SC-L-T-H+3AT. Yeast cells bearing ala mutants that expressed the lac $\mathrm{Z}$ reporter at levels lower than measured in pACT2- $\mathrm{N}_{(\mathrm{wt})}$ cells grew less well. Cells bearing ala mutants that expressed lac $\mathrm{Z}$ at similar levels to that of the wild type grew comparable to cells bearing pACT2- $\mathrm{N}_{(\mathrm{wt})}$. Results for a representative experiment are shown in Figure 3. Robust growth of cells transformed with pACT2- $\mathrm{N}_{(\mathrm{wt})}$ and pGBT9-N $\mathrm{N}_{(\mathrm{wt})}$ or with pACT2-N ${ }_{(91 \mathrm{~A})}$ and pGBT9$\mathrm{N}_{(\mathrm{wt})}$ occurred (Fig. 3, sectors 1 and 2). Cells transformed with

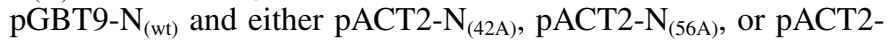
$\mathrm{N}_{(145 \mathrm{~A})}$ were not able to grow well (Fig. 3, sectors 3 to 5). Cells that did not express an N-AD or N-DB fusion at all did not grow (Fig. 3, sectors 6 to 8). Thus, results from Gal4 regulated promoters having different architecture $(26,27)$ are in complete agreement.

Wild-type and ala substitution mutants of N-AD are equally stable in yeast cells. We determined the size and relative amounts of the wild-type and ala mutant N-AD fusion proteins in yeast by Western blot analysis. Equal amounts of total protein from extracts of cells transformed with pACT2- $\mathrm{N}_{(\mathrm{wt})}$, pACT2-GFP, or the pACT2- $\mathrm{N}_{(\text {ala })}$ plasmids were separated by electrophoresis, transferred to nitrocellulose, and probed with antibodies raised against TSWV N protein. A prominent immunoreactive product of approximately $47 \mathrm{kDa}$ (the expected size of the $\mathrm{AD}-\mathrm{N}$ fusion protein) is visible in lanes containing preparations from cells trans-

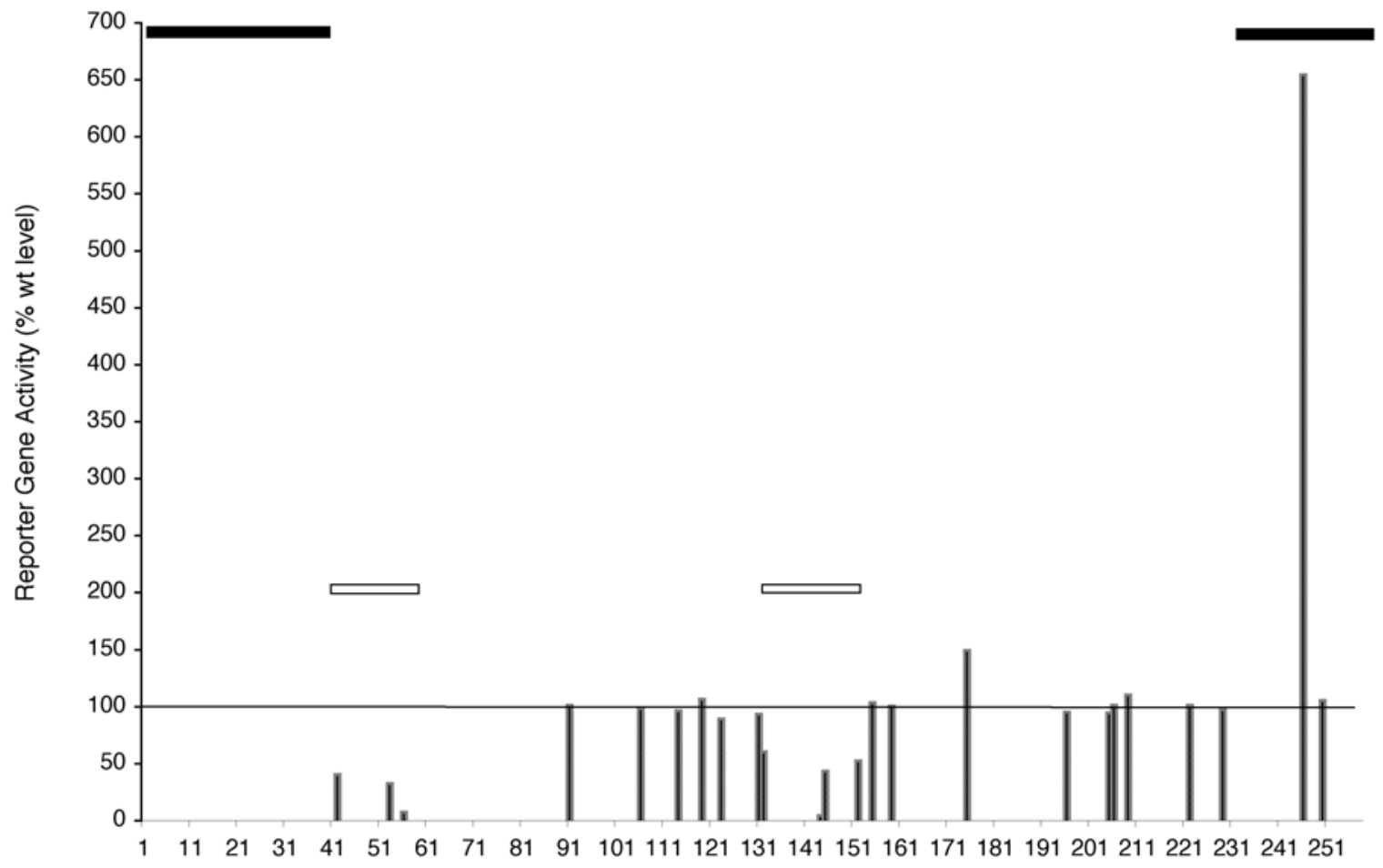

Amino Acid Residue

Fig. 2. Effect of single alanine substitutions in the Tomato spotted wilt virus $\mathrm{N}$ moiety of a Gal4 activation domain-N (AD-N) fusion on lac $\mathrm{Z}$ reporter expression in a yeast two-hybrid system. Position in the primary structure of $\mathrm{N}$ is indicated on the $x$ axis. $\beta$-Galactosidase activity expressed as a percent of expression obtained from cells bearing wild-type $\mathrm{N}$ in the AD-N fusion is indicated on the $y$ axis. The filled horizontal bars indicate regions of $\mathrm{N}$ reported by Uhrig et al. (23) as responsible for $\mathrm{N}-\mathrm{N}$ interaction. Open horizontal bars are regions identified in this study that contribute to $\mathrm{N}-\mathrm{N}$ interaction. 
formed with pACT2-N (either wild-type or ala mutant) (Fig. 4, lanes 1 and 3 to 11). As expected, the band is not present in extracts from cells transformed with pACT2-GFP (Fig. 4, lane 2). Furthermore, the band is of nearly equal intensity in all samples from pACT2-N transformants. Also visible in the samples containing the expected size immunoreactive band are small amounts of faster-migrating immunoreactive material. Control immunoblots probed with antibodies against yeast TFIIB demonstrated that equivalent amounts of this antigen were present in each sample (data not shown), confirming that lanes were loaded with similar amounts of total protein.

\section{DISCUSSION}

We have used ala scanning mutagenesis and yeast two-hybrid assays to examine the features that govern interactions between monomers of TSWV N protein. These interactions likely play a pivotal role in the assembly of TSWV RNPs.

Interactions between TSWV N protein monomers have been previously studied by Uhrig and colleagues (23). They suggested a model in which monomers of $\mathrm{N}$ interact via hydrophobic forces in a head-to-tail fashion. Our data are consistent with particular aspects of their model; however, we suggest that the head-to-tail model is not sufficient to account for all aspects of the interaction between $\mathrm{N}$ protein monomers.

Residues identified as important for $\mathrm{N}-\mathrm{N}$ interaction by our ala scan of the $\mathrm{N}$ protein are located in discrete regions in the primary structure. One region contains residues 42, 53, and 56 (Fig. 2). Another region is located between residues 131 and 155 (Fig. 2). Neither region has been identified previously as important for TSWV N-N interaction or RNP assembly. Our screen also identified two residues, 175 and 246, that, when changed to ala, result in higher expression of the reporter (Fig. 2; Table 2).

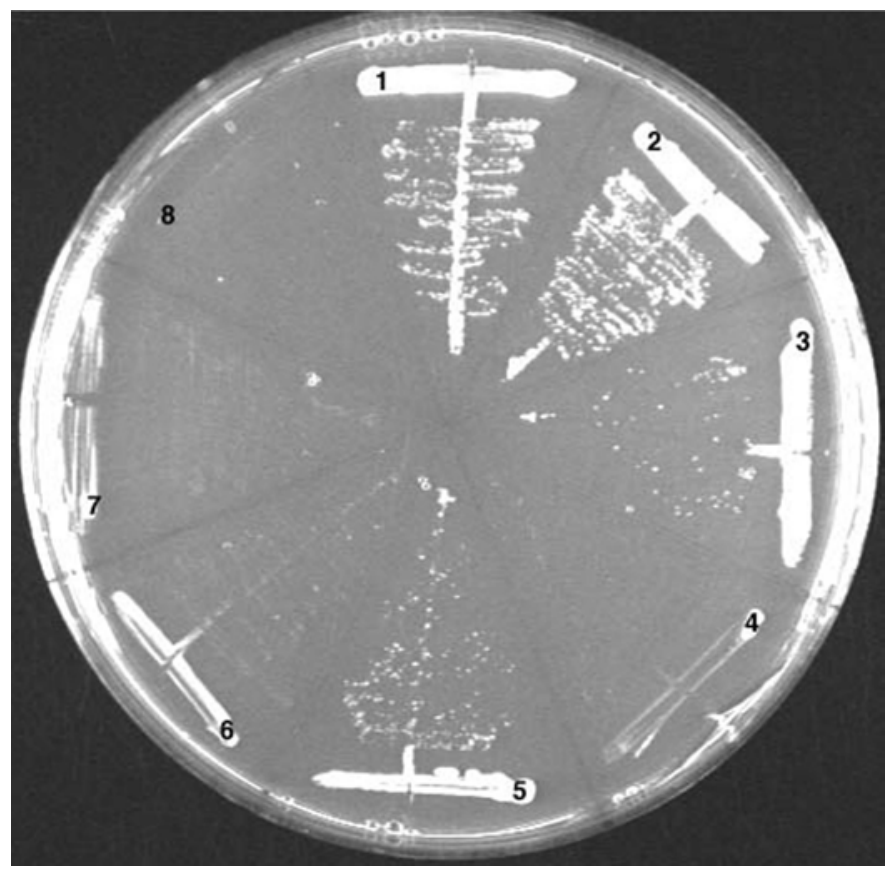

Fig. 3. Yeast two-hybrid phenotypes of yeast transformed with different combinations of pACT2 and pGBT9 when cultured on media lacking leucine, tryptophan, and histidine and amended with $50 \mathrm{mM} 3$-aminotriazole. Sector 1 , yeast strain MaV203 transformed with $\mathrm{pACT} 2-\mathrm{N}_{(\mathrm{wt})}$ and $\mathrm{pGBT} 9-\mathrm{N}_{(\mathrm{wt})}$;

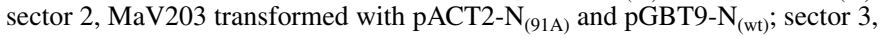
MaV203 transformed with pACT2- $\mathrm{N}_{(42 \mathrm{~A})}$ and $\mathrm{pGBT} 9-\mathrm{N}_{(\mathrm{wt})}$; sector 4, MaV203 transformed with pACT2- $\mathrm{N}_{(56 \mathrm{~A})}$ and pGBT9- $\mathrm{N}_{(\mathrm{wt})}$; sector 5, MaV203 transformed with pACT2- $\mathrm{N}_{(145 \mathrm{~A})}$ and pGBT9- $\mathrm{N}_{(\mathrm{wt})}$; sector 6, MaV203 transformed with pACT2- $\mathrm{N}_{(\mathrm{wt})}$ and pGBT9; sector 7, MaV203 transformed with pACT2-GFP and pGBT9- $\mathrm{N}_{(\mathrm{wt})}$; sector 8, MaV203 transformed with pACT2GFP and pGBT9.
Residues in $\mathrm{N}$ that, when changed to ala, resulted in reduced expression of the reporter had nonpolar or hydrophobic side chains (Table 2). Furthermore, with a single exception, all residues (identified in our initial screen as candidates for participating in $\mathrm{N}-\mathrm{N}$ interactions) having polar or charged side chains in the native $\mathrm{N}$ protein were not distinguishable from wild-type $\mathrm{N}$ when changed to ala (Table 2). The single exception was at residue 175 when a lys-to ala change resulted in increased expression of the lac Z reporter (Table 2). Thus, our data are consistent with the notion that $\mathrm{N}$ protein monomers interact with one another largely by nonelectrostatic interactions.

The ala substitution with the most dramatic effect in our experiments, F246A, is located in the C-terminal 26-amino-acid residues of the $\mathrm{N}$ protein, a region reported to be involved in $\mathrm{N}-\mathrm{N}$ interactions (23). We suggest that replacement of the phenylalanine at residue 246 with ala completely (or nearly so) disables an $\mathrm{N}$ protein interaction site in the C-terminus. The loss of activity at this site could prevent multimerization of $\mathrm{N}$ and allow for only $\mathrm{N}-\mathrm{N}$ dimers to form. Thus, $\mathrm{N}$ protein monomers lacking the C-terminal interaction site would not participate in RNP formation. However, the "dimer-only" mutants could increase the efficiency of transcription activation by the $\mathrm{N}$-mediated reconstituted Gal4 transcription factor in the yeast two-hybrid assay because the dimer-only form of the transcription factor might interact more efficiently with RNA polymerase II in the context of the promoter than would a larger multimer of $\mathrm{N}-\mathrm{AD}$ subunits that would form from interactions between $\mathrm{N}$ proteins having the $\mathrm{C}$ terminal binding face as well as other binding surfaces functioning.

The cooperative nature of N-RNA binding $(13,20,24)$ suggests that $\mathrm{N}$ monomers have two (or more) surfaces for interaction with adjacent molecules. We propose that the residues in the C-terminal 26 amino acids of TSWV N contribute to one interaction surface and that residues in the regions 42 to 56 and 132 to 152 contribute to another surface (or surfaces) for monomer interaction. The contribution of residue 175 to these proposed surfaces is not obvious. The involvement of residues from the central portions of the $\mathrm{N}$ primary structure in $\mathrm{N}-\mathrm{N}$ interactions has been reported for Hantavirus $\mathrm{N}$ proteins $(4,13,29)$. Our work represents the first report of the participation of regions other than the extreme $\mathrm{N}$ - and C-termini of TSWV N in N-N interaction.

The role of the N-terminal residues of TSWV $\mathrm{N}$ in monomer interactions remains an open question. Our data are not consistent with models involving the $\mathrm{N}$-terminus in $\mathrm{N}-\mathrm{N}$ interactions (23). Furthermore, efforts that have specifically targeted portions of the $\mathrm{N}$ gene that encode the $\mathrm{N}$ - or $\mathrm{C}$-terminal regions of the protein suggested as crucial for $\mathrm{N}-\mathrm{N}$ interaction have not identified further interaction-defective point mutants as yet (R. Pedersen and M. Kainz, unpublished data). It may be that single amino acid substitutions in the $\mathrm{N}$ terminus do not disrupt the $\mathrm{N}-\mathrm{N}$ interaction to the extent required to affect expression of our lac $\mathrm{Z}$ reporter to a measurable degree. Another possibility is that we have not yet identified all of the residues involved in the $\mathrm{N}-\mathrm{N}$ interaction with

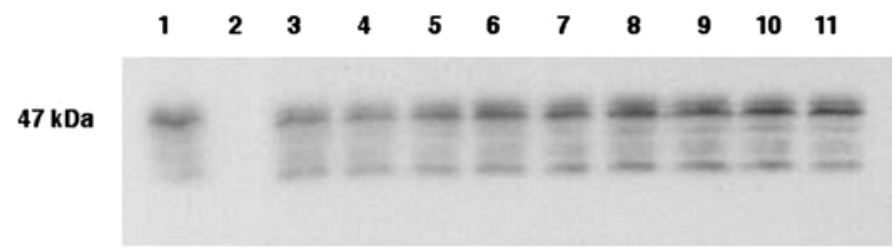

Fig. 4. Immunoblot analysis of protein extracts prepared from yeast cells transformed with pACT2 derivatives and probed with anti-Tomato spotted wilt virus $\mathrm{N}$ protein serum. Lane 1, extract from cells bearing $\mathrm{pACT} 2-\mathrm{N}_{(\mathrm{wt})}$; lane 2 , extract from cells bearing pACT2-GFP; lanes 3 to 11, extract from cells bearing pACT2- $\mathrm{N}_{(\mathrm{ala})}$ at position $42,53,56,132,144,145,152,175$, and 246, respectively. Protein molecular mass determined by comparison with Benchmark prestained standards (data not shown). 
our screens. Finally, it also is possible that $\mathrm{N}$-terminal deletions (23) may have consequences not directly related to the residues deleted, particularly when deletions are constructed in the absence of knowledge of the protein structure. In contrast, it has been demonstrated that ala substitutions (such as those reported in this article) do not significantly alter the overall structure of a protein (5). Thus, although our data do not allow us to rule out a role for the $\mathrm{N}$-terminus in $\mathrm{N}$ dimerization, we suggest that residues other than or in addition to those located in the extreme $\mathrm{N}$ terminus are involved in $\mathrm{N}$ protein dimerization or multimerization.

It is important to note that our experiments all were performed in the context of fusion proteins that function in yeast two-hybrid assays and that the tertiary structure of the TSWV N protein is not known. Therefore, models for RNP structures based on our results and those of others (23) must be regarded as tentative. Furthermore, our experiments were conducted in the absence of TSWV genomic RNA. The role, if any, of the RNA in mediating N-N interactions remains largely unexplored. Our ongoing experiments are testing the predictions of the yeast two-hybrid models for RNP assembly. Information from such experiments as well as those reported in this article should contribute to the rational design of novel intervention strategies aimed at controlling plant disease incited by TSWV.

\section{ACKNOWLEDGMENTS}

Work in M. Kainz's laboratory was supported by a grant from the Colgate University Faculty Research Council; L. Sweeney was supported by a Merck/AAAS Summer Fellowship; E. DeRose received support from the Wolk Foundation; work in T. L. German's laboratory was supported by grants from the Ohio Floriculture Commission, Mycogen Corporation, and the University of Wisconsin Graduate School; and P. Hilson was supported by grants from Mycogen Corporation and the University of Wisconsin Graduate School. We thank E. Chapman for excellent technical assistance; M. Vidal and colleagues for yeast strains, yeast two-hybrid plasmids, and advice on yeast two-hybrid experiments; A. Thompson for assistance with figure preparation; A. Whitfield for critical reading of the manuscript; and B. Hoopes and J. Sherwood for antisera.

\section{LITERATURE CITED}

1. Adams, A., Gottschlung, D. E., Kaiser, C. A., and Stearns, T. 1997. Methods in Yeast Genetics. Cold Spring Harbor Laboratory, Cold Spring Harbor, NY.

2. Adkins, S. 2000. Tomato spotted wilt virus-positive steps towards negative success. Mol. Plant Pathol. 1:151-157.

3. Adkins, S., Quadt, R., Choi, T.-J., Ahlquist, P., and German, T. 1995. An RNA-dependent RNA polymerase activity associated with virions of tomato spotted wilt virus, a plant- and insect-infecting bunyavirus. Virology 207:308-311

4. Alfadhli, A., Love, Z., Arvidson, B., Seeds, J., Willey, J., and Barklis, E. 2001. Hantavirus nucleoprotein oligomerization. J. Virol. 75:2019-2023.

5. Cunningham, B., and Wells, J. 1989. High-resolution epitope mapping of hGH-receptor interactions by alanine-scanning mutagenesis. Science 244:1081-1085.

6. Elliott, R. M. 1996. The Bunyaviridae. Plenum Press, New York.

7. Fields, S., and Song, O.-K. 1989. A novel genetic system to detect protein-protein interactions. Nature 340:245-246.

8. German, T. L., Ullman, D. E., and Moyer, J. W. 1992. Tospoviruses: Diagnosis, molecular biology, phylogeny, and vector relationships. Annu. Rev. Phytopathol. 30:315-348.
9. Gietz, R. D., Schiestl, R. H., Willems, A. R., and Woods, R. A. 1995 Studies on the transformation of intact yeast cells by the LiAc/ss-DNA/ PEG procedure. Yeast 11:355-360.

10. Gott, P., Stohwasser, R., Schnitzler, P., Darai, G., and Bautz, E. K. F. 1991. RNA binding of recombinant nucleocapsid proteins of Hantaviruses. Virology 194:332-337.

11. Kainz, M., and Gourse, R. L. 1998. The c-terminal domain of the alpha subunit of Escherichia coli RNA polymerase is required for efficient rhodependent transcription termination. J. Mol. Biol. 284:1379-1390.

12. Kaukinen, P., Koistinen, V., Vapalahti, O., Vaheri, A., and Plyusnin, A. 2001. Interaction between molecules of hantavirus nucleocapsid protein. J. Gen. Virol. 82:1845-1853.

13. Kaukinen, P., Vaheri, A., and Plyusnin, A. 2003. Mapping of the regions involved in homotypic interactions of Tula hantavirus $\mathrm{N}$ protein. J. Virol. 77:10910-10916.

14. Ma, H., Kunes, S., Schatz, P. J., and Botstein, D. 1987. Plasmid construction by homologous recombination in yeast. Gene 58:201-216.

15. Michael, S. 1994. Mutagenesis by incorporation of a phosphorylated oligo during PCR amplification. Biotechniques 16:410-412.

16. Osborne, J. C., and Elliott, R. M. 2000. RNA binding properties of Bunyamwera virus nucleocapsid protein and selective binding to an element in the $5^{\prime}$ terminus of the negative-sense S segment. J. Virol. 74:9946-9952.

17. Printen, J. A., and Sprague, G. F. 1994. Protein interactions in the yeast pheromone response pathway: Ste5p interacts with all members of the MAP kinase cascade. Genetics 138:609-619.

18. Richmond, K. E., Chenault, K., Sherwood, J. L., and German, T. L. 1998. Characterization of the nucleic acid binding properties of tomato spotted wilt virus nucleocapsid protein. Virology 248:6-11.

19. Rudolph, C., Schreier, P. H., and Uhrig, J. F. 2003. Peptide-mediated broad-spectrum plant resistance to tospoviruses. Proc. Natl. Acad. Sci. USA 100:4429-4434.

20. Sambrook, J., Fritsch, E. F., and Maniatis, T. 1989. Molecular Cloning: A Laboratory Manual, 2nd ed. Cold Spring Harbor Laboratory, Cold Spring Harbor, NY.

21. Schmaljohn, C. S. 1996. Bunyaviridae: The viruses and their replication. Pages 1447-1471 in: Fields Virology, 3rd ed. B. N. Fields, D. M. Knipe, and P. M. Howley, eds. Lippincott-Raven, Philadelphia.

22. Severson, W. B., Xu, X., and Jonsson, C. B. 2001. cis-Acting signals in encapsidation of Hantaan virus S-segment viral genomic RNA by its $\mathrm{N}$ protein. J. Virol. 75:2646-2652.

23. Uhrig, J. F., Soellick, T.-R., Minke, C. J., Philipp, C., Kellmann, J.-W., and Schreier, P. H. 1999. Homotypic interaction and multimerization of nucleocapsid protein of tomato spotted wilt tospovirus: Identification and characterization of two interacting domains. Proc. Natl. Acad. Sci. USA 96:55-60.

24. Ullman, D. E., German, T. L., Sherwood, J. L., Westcot, D. M., and Cantone, F. A. 1993. Tospovirus replication in insect vector cells: Immunocytochemical evidence that the nonstructural protein encoded by the $\mathrm{S}$ RNA of tomato spotted wilt virus is present in thrips vector cells. Phytopathology 83:456-463.

25. van Poelwijk, F., Boye, K., Oosterling, R., Peters, D., and Goldbach, R. 1993. Detection of the $\mathrm{L}$ protein of tomato spotted wilt virus. Virology 197:468-470.

26. Vidal, M. 1997. The reverse two-hybrid system. Pages 1447-1471 in: The Yeast Two Hybrid System. P. Bartel and S. Fields, eds. Oxford University Press, Oxford.

27. Vidal, M., Brachmann, R., Fattaey, A., Harlow, E., and Boeke, J. 1996. Reverse two-hybrid and one-hybrid systems to detect dissociation of protein-protein and protein-DNA interactions. Proc. Natl. Acad. Sci. USA 93:10315-10320.

28. Xu, X., Severson, W., Villegas, N., Schmaljohn, C. S., and Jonsson, C. B. 2002. The RNA binding domain of the Hantaan virus N protein maps to a central conserved region. J. Virol. 76:3301-3308.

29. Yoshimatsu, K., Lee, B-H., Araki, K., Morimatsu, M., Ogino, M., Ebihara, H., and Arikawa, J. 2003. The multimerization of hantavirus nucleocapsid protein depends on type-specific epitopes. J. Virol. 77:943-952.

30. Zhou, Y., Zhang, X., and Ebright, R. 1991. Random mutagenesis of gene sized DNA molecules by use of PCR with Taq DNA polymerase. Nucleic Acids Res. 19:6052. 